Article

\title{
Adolescent Lifestyle Behaviors, Coping Strategies and Subjective Wellbeing during the COVID-19 Pandemic: An Online Student Survey
}

\author{
Yolande Pigaiani ${ }^{1}$, Leonardo Zoccante ${ }^{2}$, Anastasia Zocca ${ }^{1}$, Athos Arzenton ${ }^{3}$, \\ Marco Menegolli ${ }^{1}$, Sabrina Fadel ${ }^{1}$, Mirella Ruggeri ${ }^{4}$ and Marco Colizzi ${ }^{2,4,5, *(D)}$ \\ 1 A.R.S.D.A. Association Research Study Alimentary Disorders, 37122 Verona, Italy; ypigaiani@tiscali.it (Y.P.); \\ anastasia.zocca@studenti.unipd.it (A.Z.); marcomene87@gmail.com (M.M.); s.fadel0101@gmail.com (S.F.) \\ 2 Child and Adolescent Neuropsychiatry Unit, Maternal-Child Integrated Care Department, \\ Integrated University Hospital of Verona, 37126 Verona, Italy; leonardo.zoccante@aovr.veneto.it \\ 3 Istituto di Istruzione Superiore Ferraris-Fermi, 37122/37138 Verona, Italy; athos.arzenton@gmail.com \\ 4 Section of Psychiatry, Department of Neurosciences, Biomedicine and Movement Sciences, \\ University of Verona, 37134 Verona, Italy; mirella.ruggeri@univr.it \\ 5 Department of Psychosis Studies, Institute of Psychiatry, Psychology and Neuroscience, \\ King's College London, London SE5 8AF, UK \\ * Correspondence: marco.colizzi@univr.it; Tel.: +39-045-812-6832
}

Received: 23 October 2020; Accepted: 6 November 2020; Published: 9 November 2020

check for updates

\begin{abstract}
Background and objectives: Adolescence represents a critical period for rapid psychophysical and socio-cognitive changes, with implications for health and wellbeing in later life. From this perspective, the manifestation of unhealthy lifestyles and dysfunctional behaviors may reflect a change in wellbeing requiring alertness and prompt intervention. This study investigated lifestyle behaviors and coping strategies among Italian adolescents, also in relation to the ongoing COVID-19 pandemic, and whether they would predict a change in subjective wellbeing. Materials and Methods: In the period between 1 April and 10 April 2020, adolescents aged 15-21 filled out an online survey consisting of 33 questions investigating socio-demographic characteristics, lifestyle behaviors, coping strategies, and subjective wellbeing. Results: Data was available on 306 participants. Most adolescents planned their daily routine (57.8\%), engaging in structured activities (17.6-67.3\%) and developing new interests (54.6\%), and gave a positive reading of the ongoing period $(57.8 \%)$, thus revealing adaptive coping strategies. Family wise, even though it was hard to stay at home $(66 \%)$ and difficulties emerged, including self-isolation (50.7\%) and quarrels (31.7\%), a relevant proportion of adolescents shared their feelings $(40.5 \%)$ and revaluated their family relationships (29.4-39.7\%). In terms of social and school engagement, almost all adolescents kept contacts with their partner, friends, and teachers (90.2-93.5\%). School commitments at home were sufficiently preserved (63.1\%), however adolescents expressed preoccupations about their educational path $(56.2 \%)$. A change in subjective wellbeing (49.3\%) and symptoms of anxiety (39.9\%) were frequently reported. A number of factors predicted a change in subjective wellbeing, including adaptive coping strategies (physical activity, OR $=2.609,95 \%$ confidence interval (CI) 1.297-5.247; engaging in different activities than before, OR $=2.212,95 \%$ CI 1.157-4.230), family issues (finding hard to stay at home, $\mathrm{OR}=3.852,95 \%$ CI 1.953-7.599; having quarrels, OR $=2.158,95 \%$ CI 1.122-4.150), school-related behaviors (fearing a negative educational outcome, $\mathrm{OR}=1.971,95 \% 1.063-3.655$ ), and female gender $(\mathrm{OR}=3.647,95 \%$ CI 1.694-7.851). Conclusions: Both personal and environmental coping resources are relevant to subjective wellbeing in adolescence and should be taken into account for prevention and early intervention in youth mental health.
\end{abstract}

Keywords: adolescence; resilience; stress; family; school; child and adolescent psychiatry; mental health prevention 


\section{Introduction}

Adolescence represents a critical period for rapid physical, social, cognitive, and emotional changes, with important implications for health and wellbeing in later life [1]. Better healthcare and nutrition, extended education, and a widespread use of new technologies, offer the possibility of this being the healthiest generation of adolescents ever [2]. However, nowadays new threats to adolescents' wellbeing have emerged, including wider availability of unhealthy products, the global youth unemployment crisis, poorer family stability, environmental deterioration, war conflicts, and mass migration [2]. Recent times have also witnessed the worldwide spread of a new viral pathogen, whose potentially deadly infectious disease, the 2019 coronavirus disease (COVID-19), may represent a stressful life event [3]. Regardless of historical period, consolidated evidence indicates that most mental health difficulties have their peak of incidence during the transition from childhood to young adulthood, affecting up to $20 \%$ of adolescents [4]. Moreover, among people younger than 25 years old, psychological and emotional difficulties account for health loss in almost one case in two [5]. From this perspective, one of the areas requiring alertness and prompt intervention is the manifestation of unhealthy lifestyles and dysfunctional behaviors, a pattern that increases with age, independent of its clinical relevance [6]. On the other hand, acquiring social-emotional skills such as self-control, self-regulation, and goal-directed behavior predicts better academic and social adjustment as well as overall youth wellbeing $[7,8]$.

Skill development during adolescence takes place within a complex social network made by family, peers, school, community, media, and other cultural influences. First, up to adolescence, families and related social conditions exert a strong influence on children's wellbeing and competencies, with long-lasting effects throughout their lifespan [9]. Second, the school system, besides sustaining adolescents through their educational objectives and verifying their learning outcomes, is a platform for wellbeing promotion. Its mentoring and social support advocacy [10] provides not only basic health knowledge (e.g., notions of sex education) but also helps developing and maintaining lifestyles that minimize health risks [2]. Third, participation and civic engagement are important aspects of adolescents' social development and personal fulfillment [1], as they engage progressively more with the wider social environment in search of a sense of community. The latter will require a new balance in the adolescent's parent-child relationship and impact on their social behaviors and wellbeing [11]. Fourth, a considerable part of the adolescents' development will happen in virtual space, as the last 30 years have seen the growing role of the internet as an instrument to create and maintain interpersonal relationships, whose opportunities and risks are constantly debated [12]. Fifth, the acquisition of health-related skills and resources would lay the foundations not only for the physical and mental wellbeing of the adolescents themselves, positively shaping their health trajectory throughout their lifespan, but also of the next generation, whom they will be parenting [13].

Altogether, evidence on the importance of sustaining health trajectories during adolescence has fueled a pro-active and positive interpretation of the wellbeing concept, understood as the progressive development of physical, emotional, and cognitive skills and not as the bare absence of negative attitudes [2]. To fully implement such change in the way adolescents' wellbeing is considered, a shift towards a more pro-active and positive approach is also required for the wider youth-oriented mental health promotion and prevention strategies [14]. For instance, in order to support adolescents to live healthy lives, a broad range of preventive interventions are required, including self-care. Self-care is particularly relevant during adolescence when the concept of self is fully developing and consolidating. It allows adolescents and their families to sustain their health through health-promoting practices, monitoring of one's own changes in habits and behaviors, and responding to occurring health threats, also at the cognitive and emotional level [15]. In fact, as for physical wellbeing, self-evaluation is crucial to promote mental and social wellbeing, as parts of the individual's overall subjective wellbeing [16]. Consistent, subjective wellbeing during adolescence has been suggested to be intimately related with good self-assessment and knowledge of one's state of health [17], positive attitudes towards life [17], 
school satisfaction [17,18], social support [7], positive social climate within family [19], engagement with healthy behaviors (e.g., physical activity) $[17,20]$, and avoidance of unhealthy habits (e.g., smoking) [17].

The purpose of this study was threefold. The main aim was to rapidly investigate lifestyle behaviors, coping strategies, and subjective wellbeing among adolescent students. Following from previous evidence [17-19], a further aim was to conduct exploratory analyses to investigate whether any sociodemographic characteristics, lifestyle behaviors or coping strategies would be associated with a change in subjective wellbeing. Finally, the survey served to characterize how adolescents' subjective wellbeing changed in relation to the ongoing COVID-19 pandemic.

\section{Materials and Methods}

\subsection{Research Design}

An online student survey was created by using Google Forms and then disseminated via a hyperlink, within the educational digital platform already adopted by each school to support management processes and to improve record-keeping of the educational process. The survey was available online from the 1 April to the 10 April 2020. All students aged 18 years and older, or parents for those students less than 18 years old, provided electronic informed consent containing information about the purpose of the study, procedures, benefits of participating, voluntary participation, and contact information of the researchers.

The survey was part of a larger study which was approved by the research ethics committee at the Integrated University Hospital of Verona (CESC 2242).

\subsection{Participants}

A nonprofit organization, with a mission to empower wellbeing by educating healthcare professionals, school personnel, advocacy and support networks about preventative health, as well as school networks with a mission to empower economic, social, cultural, civic and personal wellbeing among students by the implementation of Information and Communication Technologies and digital inclusion, were used to distribute and directly encourage survey participation. The online student survey was proposed to three Italian high schools throughout the country, which were already collaborating with the nonprofit organization and school networks. Through the involvement of the School Governing Bodies, students were asked to fill out the online survey.

\subsection{Instrument}

The student survey was developed by a focus group of physicians, psychologists, and child life specialists, also taking advice from the nonprofit organization and school networks. The survey consisted of 3 socio-demographic questions and 30 questions exploring lifestyle behaviors, coping strategies, and subjective wellbeing (29 multiple choice questions, 1 yes/no question). Participants were allowed to select only 1 item for each question.

\subsection{Analyses}

The final raw data was downloaded from Google Forms into a Microsoft Excel file for analysis using SPSS software (Version 26.0; IBM Corp, Armonk, NY, USA). Descriptive statistics were used to provide baseline information concerning students' socio-demographic characteristics, lifestyle behaviors, coping strategies, and subjective wellbeing. In order to gain interpretability and simplicity as well as take into account potentially highly skewed and/or binomial distributions, when applicable, multiple response options were also restructured into dichotomous variables by collapsing data points into high (enough/very; often/always) and low (not at all/a little; never/seldom) groups. Then, a multiple logistic regression was performed to investigate whether any students' socio-demographic characteristics, lifestyle behaviors, or coping strategies would predict a change in their subjective wellbeing.

The survey was not intended to formally conduct mental health assessments of participating students. 


\section{Results}

\subsection{Sociodemographic Characteristics}

A total of 306 adolescents participated in the survey, coming from three high schools located in Verona (56.5\%), Milan (15.7\%), and Rome (27.8\%), Italy. The mean age of participating students was 18.1 years $(\mathrm{SD}=0.9$; range: $15-21)$. Male students represented $72.9 \%$ of the sample.

A full description of survey responses, including all multiple-choice options, is provided in Tables 1 and 2. The following data reporting describes adolescent students based on the dichotomization of the sample. In particular, it refers to the high group's behavioral patterns (enough/very; often/always).

\subsection{Lifestyle Behaviors and Coping Strategies}

Following the COVID-19 emergency outbreak, an overwhelming proportion of students put an effort to respect the rules in place in everyone's best interest (95.1\%). Most students planned their daily routine (57.8\%), also deciding to organize their time in a different way (82\%) and to engage in different activities (54.6\%) than before. Most common activities were doing physical activity (67.3\%), getting interested in cooking $(47.4 \%)$, playing videogames $(36.3 \%)$, reading $(30.1 \%)$, and playing board games $(17.6 \%)$.

Even though one in every two students tended to frequently withdraw into their bedroom (50.7\%), with one third reporting a significant increase in family quarrels (31.7\%), a substantial proportion of adolescents let their parents know their feelings (40.5\%) and a slightly lower percentage revaluated their parent-child (29.4\%) or sibling relationships (39.7\%). Of those having a romantic relationship, the large majority reported missing their partner and supporting each other (90.2\%). Almost all students used social networks to keep contact with their friends (93.5\%) and some of them made new acquaintances online (19.3\%). Asked to choose between four descriptions of the ongoing period, the positive ones, that are "useful-opportunity" (30.4\%) and "support-nearness" (27.4\%), were the most selected.

Apart from a few students, all kept remote contacts with their teachers (92.2\%). Most adolescents considered positively the offered distance learning (79.1\%), reporting being able to do their homework $(63.1 \%)$ and to balance school commitments and free time $(63.1 \%)$. Personal computers were the most commonly used devices for distance learning (55.2\%). However, more than half of the students feared a negative impact of the ongoing period on their educational path (56.2\%) (Table 1$)$.

Table 1. Lifestyle behaviors and coping strategies.

\begin{tabular}{ccc}
\hline Survey Questions & $\mathbf{N}$ & $\mathbf{\%}$ \\
\hline I put an effort to respect the rules in place in everyone's best interest & & \\
Very & 195 & 63.7 \\
Enough & 96 & 31.4 \\
A little & 13 & 4.2 \\
Not at all & 2 & 0.7 \\
\hline I plan my daily routine & & \\
Very & 48 & 15.7 \\
Enough & 129 & 42.2 \\
A little & 101 & 33 \\
Not at all & 28 & 9.2 \\
\hline I decide to organize my time in a different way & & \\
Very & 92 & 30.1 \\
Enough & 159 & 52 \\
A little & 46 & 15 \\
Not at all & 9 & 2.9 \\
\hline
\end{tabular}


Table 1. Cont.

\begin{tabular}{|c|c|c|}
\hline Survey Questions & $\mathbf{N}$ & $\%$ \\
\hline \multicolumn{3}{|c|}{ I got engaged in different activities than before } \\
\hline Very & 38 & 12.4 \\
\hline Enough & 129 & 42.2 \\
\hline A little & 102 & 33.3 \\
\hline Not at all & 37 & 12.1 \\
\hline \multicolumn{3}{|l|}{ I do physical activity } \\
\hline Very & 83 & 27.1 \\
\hline Enough & 123 & 40.2 \\
\hline A little & 64 & 20.9 \\
\hline Not at all & 36 & 11.8 \\
\hline \multicolumn{3}{|c|}{ I got interested in cooking } \\
\hline Very & 38 & 12.4 \\
\hline Enough & 107 & 35 \\
\hline A little & 88 & 28.8 \\
\hline Not at all & 73 & 23.9 \\
\hline \multicolumn{3}{|l|}{ I play videogames } \\
\hline Very & 42 & 13.7 \\
\hline Enough & 69 & 22.5 \\
\hline A little & 97 & 31.7 \\
\hline Not at all & 98 & 32 \\
\hline \multicolumn{3}{|l|}{ I read } \\
\hline Very & 21 & 6.9 \\
\hline Enough & 71 & 23.2 \\
\hline A little & 119 & 38.9 \\
\hline Not at all & 95 & 31 \\
\hline \multicolumn{3}{|l|}{ I play board games } \\
\hline Very & 8 & 2.6 \\
\hline Enough & 46 & 15 \\
\hline A little & 129 & 42.2 \\
\hline Not at all & 123 & 40.2 \\
\hline \multicolumn{3}{|c|}{ I withdraw into my bedroom } \\
\hline Very & 65 & 21.2 \\
\hline Enough & 90 & 29.4 \\
\hline A little & 98 & 32 \\
\hline Not at all & 53 & 17.3 \\
\hline \multicolumn{3}{|c|}{ I argue more easily with my family } \\
\hline Very & 21 & 6.9 \\
\hline Enough & 76 & 24.8 \\
\hline A little & 113 & 36.9 \\
\hline Not at all & 96 & 31.4 \\
\hline \multicolumn{3}{|c|}{ I share my feelings with my family } \\
\hline Very & 25 & 8.2 \\
\hline Enough & 99 & 32.4 \\
\hline A little & 104 & 34 \\
\hline Not at all & 78 & 25.5 \\
\hline \multicolumn{3}{|c|}{ I've been revaluating my relationship with my parents } \\
\hline Very & 15 & 4.9 \\
\hline Enough & 75 & 24.5 \\
\hline A little & 120 & 39.2 \\
\hline Not at all & 96 & 31.4 \\
\hline
\end{tabular}


Table 1. Cont

\begin{tabular}{|c|c|c|}
\hline Survey Questions & $\mathbf{N}$ & $\%$ \\
\hline \multicolumn{3}{|c|}{ I've been revaluating my relationship with my siblings } \\
\hline Very & 17 & 6.5 \\
\hline Enough & 87 & 33.2 \\
\hline A little & 86 & 32.8 \\
\hline Not at all & 72 & 27.5 \\
\hline I'm only child & 44 & \\
\hline \multicolumn{3}{|c|}{ If I have a partner, how much I miss him/her and support each other } \\
\hline Very & 126 & 58.6 \\
\hline Enough & 68 & 31.6 \\
\hline A little & 16 & 7.4 \\
\hline Not at all & 5 & 2.3 \\
\hline I'm single & 91 & \\
\hline \multicolumn{3}{|c|}{ I use social networks to keep in contact with my friends } \\
\hline Very & 181 & 59.2 \\
\hline Enough & 105 & 34.3 \\
\hline A little & 18 & 5.9 \\
\hline Not at all & 2 & 0.7 \\
\hline \multicolumn{3}{|c|}{ I'm making new acquaintances on social networks } \\
\hline Very & 22 & 7.2 \\
\hline Enough & 37 & 12.1 \\
\hline A little & 99 & 32.4 \\
\hline Not at all & 148 & 48.4 \\
\hline \multicolumn{3}{|c|}{ Choose which couple of words best describes the ongoing period } \\
\hline Useful—opportunity & 92 & 30.4 \\
\hline Support-nearness & 83 & 27.4 \\
\hline Useless-frustration & 54 & 17.8 \\
\hline Conflict—tension & 74 & 24.4 \\
\hline Missing & 3 & \\
\hline \multicolumn{3}{|c|}{ I maintain remote contacts with my teachers } \\
\hline Very & 123 & 40.2 \\
\hline Enough & 159 & 52 \\
\hline A little & 23 & 7.5 \\
\hline Not at all & 1 & 0.3 \\
\hline \multicolumn{3}{|c|}{ How do I evaluate the offered distance learning in my school } \\
\hline Exhaustive & 61 & 19.9 \\
\hline Sufficiently adequate & 181 & 59.2 \\
\hline Not very exhaustive & 43 & 14.1 \\
\hline Poor & 16 & 5.2 \\
\hline Inadequate & 5 & 1.6 \\
\hline \multicolumn{3}{|c|}{ I am able to work at home and do my homework quietly } \\
\hline Yes & 193 & 63.1 \\
\hline No & 113 & 36.9 \\
\hline \multicolumn{3}{|c|}{ I am able to balance school commitments and free time } \\
\hline Very & 46 & 15 \\
\hline Enough & 147 & 48 \\
\hline A little & 81 & 26.5 \\
\hline Not at all & 32 & 10.5 \\
\hline \multicolumn{3}{|c|}{ Which device do I use most frequently for distance learning } \\
\hline Notebook & 29 & 9.5 \\
\hline PC Desktop & 169 & 55.2 \\
\hline Smartphone & 84 & 27.5 \\
\hline Tablet & 24 & 7.8 \\
\hline
\end{tabular}


Table 1. Cont.

\begin{tabular}{ccc}
\hline Survey Questions & $\mathbf{N}$ & $\mathbf{\%}$ \\
\hline I think that this period will affect my educational path & & \\
Yes. in a positive way & 66 & 21.6 \\
Yes. in a negative way & 172 & 56.2 \\
No. it's all the same & 68 & 22.2 \\
\hline
\end{tabular}

\subsection{Subjective Wellbeing}

For most students, it was hard to stay at home ( $66 \%)$. One in two students felt considerably changed by the experience of the pandemic $(50.7 \%)$ and noticed a significant change in their psychological wellbeing (49.3\%). More than one third reported being particularly anxious about the ongoing situation $(39.9 \%)$. Even though three out of four students reported going to bed late often or always ( $81 \%)$, most of them self-evaluated their sleep-waking cycle as generally preserved (59.2\%) (Table 2).

Table 2. Subjective wellbeing.

\begin{tabular}{|c|c|c|}
\hline Items & $\mathbf{N}$ & $\%$ \\
\hline \multicolumn{3}{|c|}{ How hard do I find to stay at home } \\
\hline Very & 120 & 39.2 \\
\hline Enough & 82 & 26.8 \\
\hline A little & 73 & 23.9 \\
\hline Not at all & 31 & 10.1 \\
\hline \multicolumn{3}{|c|}{ I think this experience changed myself } \\
\hline Very & 28 & 9.2 \\
\hline Enough & 127 & 41.5 \\
\hline A little & 105 & 34.3 \\
\hline Not at all & 46 & 15 \\
\hline \multicolumn{3}{|c|}{$\begin{array}{l}\text { I noticed significant changes in my psychological } \\
\text { wellbeing }\end{array}$} \\
\hline Very & 55 & 18 \\
\hline Enough & 96 & 31.4 \\
\hline A little & 92 & 30.1 \\
\hline Not at all & 63 & 20.6 \\
\hline \multicolumn{3}{|c|}{ I feel anxious about the ongoing situation } \\
\hline Very & 37 & 12.1 \\
\hline Enough & 85 & 27.8 \\
\hline A little & 115 & 37.6 \\
\hline Not at all & 69 & 22.5 \\
\hline \multicolumn{3}{|c|}{ I go to bed late } \\
\hline Always & 109 & 35.6 \\
\hline Often & 139 & 45.4 \\
\hline Seldom & 46 & 15 \\
\hline Never & 12 & 3.9 \\
\hline \multicolumn{3}{|c|}{ I am able to preserve a balanced sleep-waking cycle } \\
\hline Always & 63 & 20.6 \\
\hline Often & 118 & 38.6 \\
\hline Seldom & 88 & 28.8 \\
\hline Never & 37 & 12.1 \\
\hline
\end{tabular}

\subsection{Predictors of Change in Subjective Wellbeing}

A multiple logistic regression tested for an effect of the investigated socio-demographic characteristics, lifestyle behaviors, and coping strategies on the subjective change in psychological wellbeing. The logistic regression model was statistically significant, $\chi 2(28, N=303)=125.935$, 
$p<0.001$. The model explained $45.3 \%$ (Nagelkerke R2) of the variance and correctly classified $76.9 \%$ of cases.

Students who found it hard to stay at home (OR $=3.852,95 \%$ confidence interval (CI) 1.953-7.599), argued more easily with family members ( $\mathrm{OR}=2.158,95 \% \mathrm{CI} 1.122-4.150)$, and feared a negative impact of the ongoing period on their educational path (OR $=1.971,95 \%$ CI 1.063-3.655), were all more likely to report a subjective change in their psychological wellbeing. Interestingly, being female (OR $=3.647,95 \%$ CI 1.694-7.851), doing physical activity (OR $=2.609,95 \%$ CI 1.297-5.247), and engaging in different activities than before ( $\mathrm{OR}=2.212,95 \% \mathrm{CI} 1.157-4.230)$, were all associated with a higher likelihood of reporting a subjective change in one's psychological wellbeing. Furthermore, reevaluating the parent-child relationship and feeling anxious about the ongoing situation were both weakly associated with a change in one's psychological wellbeing.

Instead, students describing the ongoing period with positive words (e.g., Useful—opportunity; Support-nearness) were less likely to report a subjective change in wellbeing (OR $=0.377,95 \%$ CI 0.194-0.735). Also, being able to work at home and do personal homework quietly was weakly associated with a lower likelihood of reporting a subjective change in one's psychological wellbeing (Table 3).

Table 3. Predictors of change in subjective wellbeing.

\begin{tabular}{|c|c|c|c|c|c|c|}
\hline & B & S.E. & $\begin{array}{c}\text { Wald } \\
\text { Chi-Square }\end{array}$ & $p$-Value & OR & 95\% C.I. \\
\hline Gender (female) & 1.294 & 0.391 & 10.937 & 0.001 & 3.647 & $1.694-7.851$ \\
\hline Age & -0.155 & 0.170 & 0.833 & 0.361 & 0.856 & $0.614-1.195$ \\
\hline I put an effort to respect the rules in place & 0.335 & 0.659 & 0.258 & 0.611 & 1.398 & $0.384-5.089$ \\
\hline I plan my daily routine & -0.062 & 0.352 & 0.031 & 0.861 & 0.940 & $0.471-1.876$ \\
\hline I decide to organize my time in a different way & -0.058 & 0.401 & 0.021 & 0.885 & 0.943 & $0.430-2.072$ \\
\hline I got engaged in different activities than before & 0.794 & 0.331 & 5.766 & 0.016 & 2.212 & $1.157-4.230$ \\
\hline I do physical activity & 0.959 & 0.356 & 7.237 & 0.007 & 2.609 & $1.297-5.247$ \\
\hline I got interested in cooking & -0.164 & 0.313 & 0.274 & 0.600 & 0.849 & $0.459-1.569$ \\
\hline I play videogames & 0.189 & 0.328 & 0.331 & 0.565 & 1.208 & $0.635-2.297$ \\
\hline I read & -0.222 & 0.357 & 0.387 & 0.534 & 0.801 & $0.398-1.611$ \\
\hline I play board games & -0.554 & 0.436 & 1.617 & 0.204 & 0.575 & $0.245-1.350$ \\
\hline I withdraw into my bedroom & 0.367 & 0.319 & 1.324 & 0.250 & 1.444 & $0.772-2.699$ \\
\hline I argue more easily with my family & 0.769 & 0.334 & 5.312 & 0.021 & 2.158 & $1.122-4.150$ \\
\hline I share my feelings with my family & -0.392 & 0.351 & 1.248 & 0.264 & 0.676 & $0.340-1.344$ \\
\hline I have been revaluating my relationship with my parents & 0.601 & 0.358 & 2.827 & 0.093 & 1.824 & $0.905-3.676$ \\
\hline I use social networks to keep in contact with my friends & 1.030 & 0.689 & 2.236 & 0.135 & 2.802 & $0.726-10.812$ \\
\hline I am making new acquaintances on social networks & -0.087 & 0.376 & 0.053 & 0.817 & 0.917 & $0.439-1.915$ \\
\hline Words best describing the ongoing period (positive) & -0.975 & 0.340 & 8.220 & 0.004 & 0.377 & $0.194-0.735$ \\
\hline I maintain remote contacts with my teachers & 0.092 & 0.564 & 0.027 & 0.870 & 1.097 & $0.363-3.313$ \\
\hline I evaluate the offered distance learning positively & 0.475 & 0.376 & 1.592 & 0.207 & 1.608 & $0.769-3.362$ \\
\hline I am able to work at home and do homework quietly & -0.556 & 0.337 & 2.727 & 0.099 & 0.574 & $0.297-1.109$ \\
\hline I am able to balance school commitments and free time & -0.023 & 0.351 & 0.004 & 0.948 & 0.977 & $0.491-1.944$ \\
\hline This period will negatively affect my educational path & 0.678 & 0.315 & 4.635 & 0.031 & 1.971 & $1.063-3.655$ \\
\hline I find hard to stay at home & 1.349 & 0.347 & 15.144 & $<0.001$ & 3.852 & $1.953-7.599$ \\
\hline I think this experience changed myself & 0.421 & 0.328 & 1.649 & 0.199 & 1.523 & $0.801-2.894$ \\
\hline I feel anxious about the ongoing situation & 0.581 & 0.342 & 2.881 & 0.090 & 1.787 & $0.914-3.493$ \\
\hline I go to bed late & 0.339 & 0.428 & 0.628 & 0.428 & 1.404 & $0.607-3.247$ \\
\hline I am able to preserve a balanced sleep-waking cycle & -0.493 & 0.333 & 2.190 & 0.139 & 0.611 & $0.318-1.173$ \\
\hline
\end{tabular}

\section{Discussion}

The current study aimed to extend prior research on lifestyle behaviors and coping strategies during the adolescent period, also focusing on how such mechanisms can predict adolescents' subjective well-being in general and at times of potential psychosocial crisis as the COVID-19 emergency outbreak in particular. Results from this survey suggest a number of "active" and planning" adaptive coping strategies. In particular, most adolescents reported being organized and purposeful in their use of time, spending it in structured activities and developing new interests, and gave a positive reading of the ongoing period. In terms of family support, on one hand it was certainly hard to stay at home for most adolescent students and difficulties in family functioning emerged, with self-isolation and quarrels being frequently reported. However, despite such maladaptive coping styles, on the other hand 
a relevant proportion of adolescents shared their feelings and revaluated their family relationships. In terms of social support, almost all adolescents remained in contact with their partner and friends, supporting each other. With reference to school engagement, almost all adolescents had contacts with their teachers, however school commitments at home appeared to be only sufficiently preserved, and a large proportion of students expressed preoccupations about their educational path. Regarding their subjective wellbeing, about one in two adolescents experienced a relevant change and one in three reported symptoms of anxiety.

When assessing the impact of adolescents' lifestyle behaviors and coping strategies on their psychological wellbeing, a number of variables predicted a significant change. "Active" and planning" adaptive coping strategies associated with a significant change in wellbeing included doing physical activity and engaging in different activities than before. This is consistent with evidence that self-regulation, choice, active response, and volition are adaptive to performance [21,22]. Self-control enables children and adolescents to cope with the experience of emotional challenges or difficult situations [23].

Family-related behaviors predicting a change in wellbeing included finding it hard to stay at home, having quarrels, and, at a trend level, reevaluating the parent-child relationship. Regarding the potential impact of family difficulties on the ability of adolescents to sustain their own wellbeing, evidence on whether the manifestation of higher negative affect would also be associated with decreased positive affect is far from unequivocal [24]. Adolescents may respond to family difficulties in various ways, depending on the activation of this or that coping strategy [25].

At the school level, fearing a negative educational outcome predicted a subjective change in the psychological wellbeing. Instead, at a trend level, adolescents being able to quietly study at home, were less likely to perceive a change in their wellbeing. These findings extend previous evidence that higher school demands are associated with more perceived stress while schools can promote student wellbeing by providing clear and timely information and teacher support to the students [26].

Furthermore, male and female adolescents differed in self-report wellbeing, with females reporting a subjective change more likely. This is in line with previous evidence that females tend to assess events as more severe than males, possibly because of their ability to express a larger range of stronger and more complex emotions [27-29]. Also, with reference to the perception of the ongoing period, feeling anxious about it was weakly associated with a change in wellbeing, while those adolescents describing it positively were less likely to perceive a change in their wellbeing.

Surveys conducted during past infectious diseases with pandemic potential have allowed to collect timely data to provide evidence-based response strategies [30]. Consistent, the current online survey turned out to be a successful data gathering solution, whose advantages were the possibility to study a sufficiently large sample and expedite response times and data processing, also reducing costs [31]. Also, thanks to the support of the nonprofit organization and school networks as well as the involvement of School Governing Bodies, we limited the risk of noncontact or refusals that can reduce the response rate and representativeness of the sample, gathering data from more than three hundred adolescents in three different Italian regions. Nevertheless, results of this survey need to be interpreted in light of its limitations. Specifically, despite the previously mentioned strengths, coping strategies and subjective wellbeing were not assessed using standardized instruments, limiting the possibility to compare results between different studies or data collected at different time points from the same subjects.

\section{Conclusions}

Subjective wellbeing represents a major life goal and is crucial to optimal flourishing and functioning at the psychological, physical, and interpersonal level [32]. Consistent with this, it is used as a key outcome in several fields of psychology and mental health [33]. Even though most studies examining subjective wellbeing have traditionally focused on adult populations, recent years have witnessed an upsurge of interest in the role of subjective wellbeing for adolescent health 
and development [34-38]. In particular, during normative adolescence, attaining high levels of subjective wellbeing may reflect a successful and constructive psychosocial adjustment to one of the most rapid phases of human development [39]. Achieving subjective wellbeing is of even greater importance when adolescents additionally experience a stressful life event, due to its critical role in coping with the demands of the stressful situation, becoming resilient with respect to the negative event, and thus avoiding a functional impairment [40]. Resilient adolescents, who show the ability to recover from negative experiences, have been suggested to adapt more easily to the ever-changing demands of their transition age and to be less susceptible to the impact of unhealthy lifestyle behaviors on wellbeing [41]. Such evidence has important implications for the investigation of risk factors [42] as well as the development of effective early intervention and prevention strategies for mental health difficulties in youth [14].

In sum, this study focused on adolescents' subjective wellbeing as a function of their lifestyle behaviors and coping strategies. Evidence from this study indicates that with regard to the role played by developmental factors, adolescents' age did not predict any change in subjective well-being, whereas gender did, with females reporting such a change more likely. Also, both personal and environmental coping resources resulted to be relevant to subjective wellbeing in adolescence, including pursuing different activities such as physical activity on one hand, and receiving family as well as school support on the other.

Author Contributions: Conceptualization, Y.P., L.Z., A.Z., A.A., M.M., S.F., M.R., and M.C.; methodology, Y.P., L.Z., A.Z., A.A., M.M., S.F., M.R., and M.C.; validation, Y.P., L.Z., A.Z., M.R., and M.C.; formal analysis, Y.P., L.Z., A.Z., M.R., and M.C.; investigation, Y.P., L.Z., A.Z., A.A., M.M., S.F., M.R., and M.C.; resources, Y.P., L.Z., A.Z., A.A., M.M., S.F., M.R., and M.C.; data curation, Y.P., L.Z., A.Z., M.R., and M.C.; writing-Original draft preparation, Y.P. and M.C.; writing-Review and editing, Y.P., L.Z., A.Z., A.A., M.M., S.F., M.R., and M.C.; visualization, Y.P., L.Z., A.Z., M.R., and M.C.; supervision, M.C.; project administration, Y.P. All authors have read and agreed to the published version of the manuscript.

Funding: This research did not receive any specific grant from funding agencies in the public, commercial, or not-for-profit sectors.

Acknowledgments: The authors would like to thank the survey participants and their families for their cooperation and commitment as well as acknowledge support from the nonprofit organization and school networks.

Conflicts of Interest: The authors declare no conflict of interest.

\section{References}

1. Azzopardi, P.S.; Hearps, S.J.C.; Francis, K.L.; Kennedy, E.C.; Mokdad, A.H.; Kassebaum, N.J.; Lim, S.; Irvine, C.M.S.; Vos, T.; Brown, A.D.; et al. Progress in adolescent health and wellbeing: Tracking 12 headline indicators for 195 countries and territories, 1990-2016. Lancet 2019, 393, 1101-1118. [CrossRef]

2. Patton, G.C.; Sawyer, S.M.; Santelli, J.S.; Ross, D.A.; Afifi, R.; Allen, N.B.; Arora, M.; Azzopardi, P.; Baldwin, W.; Bonell, C.; et al. Our future: A Lancet commission on adolescent health and wellbeing. Lancet 2016, 387, 2423-2478. [CrossRef]

3. Lima, C.K.T.; Carvalho, P.M.M.; Lima, I.A.A.S.; Nunes, J.V.A.O.; Saraiva, J.S.; de Souza, R.I.; da Silva, C.G.L.; Neto, M.L.R. The emotional impact of Coronavirus 2019-nCoV (new Coronavirus disease). Psychiatry Res. 2020, 287, 112915. [CrossRef]

4. Kessler, R.C.; Berglund, P.; Demler, O.; Jin, R.; Merikangas, K.R.; Walters, E.E. Lifetime prevalence and age-of-onset distributions of DSM-IV disorders in the National Comorbidity Survey Replication. Arch. Gen. Psychiatry 2005, 62, 593-602. [CrossRef]

5. Gore, F.M.; Bloem, P.J.; Patton, G.C.; Ferguson, J.; Joseph, V.; Coffey, C.; Sawyer, S.M.; Mathers, C.D. Global burden of disease in young people aged 10-24 years: A systematic analysis. Lancet 2011, 377, 2093-2102. [CrossRef]

6. Mayne, S.L.; Virudachalam, S.; Fiks, A.G. Clustering of unhealthy behaviors in a nationally representative sample of U. S. children and adolescents. Prev. Med. 2020, 130, 105892. [CrossRef]

7. Ronen, T.; Seeman, A. Subjective well being of adolescents in boarding schools under threat of war. J. Trauma. Stress 2007, 20, 1053-1062. [CrossRef] 
8. Abrahams, L.; Pancorbo, G.; Primi, R.; Santos, D.; Kyllonen, P.; John, O.P.; De Fruyt, F. Social-Emotional skill assessment in children and adolescents: Advances and challenges in personality, clinical, and educational contexts. Psychol. Assess. 2019, 31, 460-473. [CrossRef]

9. Garg, A.; Homer, C.J.; Dworkin, P.H. Addressing Social Determinants of Health: Challenges and Opportunities in a Value-Based Model. Pediatrics 2019, 143, e20182355. [CrossRef]

10. Lombardi, E.; Traficante, D.; Bettoni, R.; Offredi, I.; Giorgetti, M.; Vernice, M. The Impact of School Climate on Well-Being Experience and School Engagement: A Study With High-School Students. Front. Psychol. 2019, 10, 2482. [CrossRef]

11. Coulombe, S.; Krzesni, D.A. Associations between sense of community and wellbeing: A comprehensive variable and person-centered exploration. J. Commun. Psychol. 2019, 47, 1246-1268. [CrossRef]

12. Valkenburg, P.M.; Peter, J. Online communication among adolescents: An integrated model of its attraction, opportunities, and risks. J. Adolesc. Health 2011, 48, 121-127. [CrossRef]

13. Sawyer, S.M.; Afifi, R.A.; Bearinger, L.H.; Blakemore, S.J.; Dick, B.; Ezeh, A.C.; Patton, G.C. Adolescence: A foundation for future health. Lancet 2012, 379, 1630-1640. [CrossRef]

14. Colizzi, M.; Lasalvia, A.; Ruggeri, M. Prevention and early intervention in youth mental health: Is it time for a multidisciplinary and trans-diagnostic model for care? Int. J. Ment. Health Syst. 2020, 14, 1-14. [CrossRef]

15. Riegel, B.; Dunbar, S.B.; Fitzsimons, D.; Freedland, K.E.; Lee, C.S.; Middleton, S.; Stromberg, A.; Vellone, E.; Webber, D.E.; Jaarsma, T. Self-care research: Where are we now? Where are we going? Int. J. Nurs. Stud. 2019. [CrossRef]

16. Mann, M.; Hosman, C.M.; Schaalma, H.P.; de Vries, N.K. Self-esteem in a broad-spectrum approach for mental health promotion. Health Educ. Res. 2004, 19, 357-372. [CrossRef] [PubMed]

17. Katja, R.; Päivi, A.K.; Marja-Terttu, T.; Pekka, L. Relationships among adolescent subjective well-being, health behavior, and school satisfaction. J. Sch. Health 2002, 72, 243-249. [CrossRef] [PubMed]

18. Steinmayr, R.; Heyder, A.; Naumburg, C.; Michels, J.; Wirthwein, L. School-Related and Individual Predictors of Subjective Well-Being and Academic Achievement. Front. Psychol. 2018, 9, 2631. [CrossRef]

19. Rask, K.; Astedt-Kurki, P.; Paavilainen, E.; Laippala, P. Adolescent subjective well-being and family dynamics. Scand. J. Caring Sci. 2003, 17, 129-138.

20. Biddle, S.J.; Asare, M. Physical activity and mental health in children and adolescents: A review of reviews. Br. J. Sports Med. 2011, 45, 886-895. [CrossRef]

21. Muraven, M.; Collins, R.L.; Shiffman, S.; Paty, J.A. Daily fluctuations in self-control demands and alcohol intake. Psychol. Addict. Behav. 2005, 19, 140-147. [CrossRef]

22. Vohs, K.D.; Baumeister, R.F.; Schmeichel, B.J.; Twenge, J.M.; Nelson, N.M.; Tice, D.M. Making choices impairs subsequent self-control: A limited-resource account of decision making, self-regulation, and active initiative. J. Pers. Soc. Psychol. 2008, 94, 883-898. [CrossRef]

23. Farley, J.P.; Kim-Spoon, J. Parenting and Adolescent Self-Regulation Mediate between Family Socioeconomic Status and Adolescent Adjustment. J. Early Adolesc. 2017, 37, 502-524. [CrossRef]

24. Zautra, A.J.; Johnson, L.M.; Davis, M.C. Positive affect as a source of resilience for women in chronic pain. J. Consult. Clin. Psychol. 2005, 73, 212-220. [CrossRef]

25. Coleman, J.; Hagell, A. Adolescence, Risk and Resilience: Against the Odds; Wiley: Chicester, UK, 2007.

26. Östberg, V.; Plenty, S.; Låftman, S.B.; Modin, B.; Lindfors, P. School Demands and Coping Resources-Associations with Multiple Measures of Stress in Mid-Adolescent Girls and Boys. Int. J. Environ. Res. Public Health 2018, 15, 2143. [CrossRef]

27. Seiffge-Krenke, I. Coping behavior of Finnish adolescents: Remarks on a cross-cultural comparison. Scand. J. Psychol. 1992, 33, 301-314. [CrossRef]

28. Frydenberg, E.; Lewis, R. Adolescent coping: The different ways in which boys and girls cope. J. Adolesc. 1991, 14, 119-133. [CrossRef]

29. Frydenberg, E.; Lewis, R. Boys play sport and girls turn to others: Age, gender and ethnicity as determinants of coping. J. Adolesc. 1993, 16, 253-266. [CrossRef]

30. Abir, M.; Moore, M.; Chamberlin, M.; Koenig, K.; Hirshon, J.; Singh, C.; Schneider, S.; Cantrill, S. Using Timely Survey-Based Information Networks to Collect Data on Best Practices for Public Health Emergency Preparedness and Response: Illustrative Case From the American College of Emergency Physicians' Ebola Surveys. Disaster Med. Public Health Prep. 2016, 10, 681-690. [CrossRef] 
31. Evans, J.; Mathur, A. The value of online surveys: A look back and a look ahead. Int. Res. 2018, $28,854-887$. [CrossRef]

32. Busseri, M.A. Toward a Resolution of the Tripartite Structure of Subjective Well-Being. J. Personal. 2015, 83, 413-428. [CrossRef]

33. Martela, F.; Ryan, R.M. The Benefits of Benevolence: Basic Psychological Needs, Beneficence, and the Enhancement of Well-Being. J. Personal. 2016, 84, 750-764. [CrossRef]

34. Wu, X.; Gai, X.; Wang, W. Subjective well-being and academic performance among middle schoolers: A two-wave longitudinal study. J. Adolesc. 2020, 84, 11-22. [CrossRef]

35. Wang, S.; Zhao, Y.; Li, J.; Lai, H.; Qiu, C.; Pan, N.; Gong, Q. Neurostructural correlates of hope: Dispositional hope mediates the impact of the SMA gray matter volume on subjective well-being in late adolescence. Soc. Cogn. Affect. Neurosci. 2020, 15, 395-404. [CrossRef]

36. Ortuño-Sierra, J.; Aritio-Solana, R.; Fonseca-Pedrero, E. New Evidences about Subjective Well-Being in Adolescence and Its Links with Neurocognitive Performance. Int. J. Environ. Res. Public Health 2020, 17, 1866. [CrossRef] [PubMed]

37. Cejudo, J.; Losada, L.; Feltrero, R. Promoting Social and Emotional Learning and Subjective Well-Being: Impact of the "Aislados" Intervention Program in Adolescents. Int. J. Environ. Res. Public Health 2020, 17, 609. [CrossRef]

38. Víllora, B.; Larrañaga, E.; Yubero, S.; Alfaro, A.; Navarro, R. Relations among Poly-Bullying Victimization, Subjective Well-Being and Resilience in a Sample of Late Adolescents. Int. J. Environ. Res. Public Health 2020, 17, 590. [CrossRef]

39. Yang, Q.; Tian, L.; Huebner, E.S.; Zhu, X. Relations among academic achievement, self-esteem, and subjective well-being in school among elementary school students: A longitudinal mediation model. Sch. Psychol. 2019, 34, 328-340. [CrossRef]

40. Dahl, R.E. Affect regulation, brain development, and behavioral/emotional health in adolescence. CNS Spectr. 2001, 6, 60-72. [CrossRef]

41. Skrove, M.; Romundstad, P.; Indredavik, M.S. Resilience, lifestyle and symptoms of anxiety and depression in adolescence: The Young-HUNT study. Soc. Psychiatry Psychiatr. Epidemiol. 2013, 48, 407-416. [CrossRef]

42. Cortese, S.; Falissard, B.; Angriman, M.; Pigaiani, Y.; Banzato, C.; Bogoni, G.; Pellegrino, M.; Cook, S.; Pajno-Ferrara, F.; Bernardina, B.D.; et al. The relationship between body size and depression symptoms in adolescents. J. Pediatr. 2009, 154, 86-90. [CrossRef]

Publisher's Note: MDPI stays neutral with regard to jurisdictional claims in published maps and institutional affiliations.

(C) 2020 by the authors. Licensee MDPI, Basel, Switzerland. This article is an open access article distributed under the terms and conditions of the Creative Commons Attribution (CC BY) license (http://creativecommons.org/licenses/by/4.0/). 